\title{
The Management
}

\section{of Adolescent Pregnancy}

\section{and Prevention}

\section{of Repeat Pregnancies}

JOSEPH L. RAUH, M.D.

LOIS B. JOHNSON, M.D.

ROBERT L. BURKET, M.D.

$\mathbf{P}$ regnancy is a major health problem among adolescents today. Physicians and other health professionals clearly recognize that the unmarried adolescent girl is often at risk for pregnancy. In addition, the parous adolescent girl may be at considerable risk for repeated pregnancy unless she practices contraception. This report describes a comprehensive care program of the Cincinnati Adolescent
Clinic which encompasses both the care of the pregnant teenager and the prevention of out-ofwedlock pregnancy.

\section{The Clinic's Comprehensive Care Program}

Adolescent Clinic. The Adolescent Clinic, located at Cincinnati General Hospital, began in 1960 as a project of the department of pediatrics of the 
University of Cincinnati Medical Center. The clinic emphasizes the evaluation and treatment of many of the major medical problems of adolescenceobesity, diabetes, epilepsy, asthma, prevention of rheumatic fever, mental retardation, growth retardation, and school maladjustment. Two of the authors, J. L. R. and R. L. B., helped establish the clinic and soon recognized that the staff should be concerned with the medical care and social problems of the pregnant girl.

Staff and method of operation. The clinic has always functioned as an age-oriented facility. New patients are usually 12 to 18 years of age. Parents are interviewed initially, but patients are then encouraged to come alone on subsequent visits. The staff physician, usually a pediatrician or internist, does the basic medical examination and followup. The same physician sees the patient at each visit. Patients may call this physician in the office or at home for episodic problems. Consultants come to the clinic at designated times.

The consulting obstetrician-gynecologist, R. L. B., supervises all girls being seen for pregnancy or birth control treatment, although followup visits for prenatal care and birth control are generally managed by the patient's staff physician. At the time of delivery, Adolescent Clinic patients are admitted to the maternity service of the Cincinnati General Hospital; parturition is managed by the intern and resident house staff-as were the deliveries of a group described subsequently. After discharge they return to the clinic for post partum care, assistance in returning to school, and birth control services.

The clinic has the services of eight part-time physicians as well as two medical caseworkers. The workers see the girls in the clinic and also in the hospital after delivery. They are especially important to the medical staff as a liaison between the patient and her family. In addition, they coordinate educational services (for example, sex education and physiology of pregnancy) and community services (such as return to school). A staff psychiatrist is available for consultation. Patients with difficult problems are discussed in multidisciplinary staff conferences.

The clinic is open five mornings a week including Saturday. Pregnant and post partum girls are usually scheduled for appointments when R. L. B. is in the clinic, although they may come at any time. The staff strives to function as a team and to maintain an understanding attitude about the
The authors are with the Adolescent Clinic at Cincinnati General Hospital, Cincinnati, Ohio. The clinic is a project of the department of pediatrics, University of Cincinnati Medical Center. Dr. Rauh is the director, Dr. Johnson is associate director, and Dr. Burket is the consulting obstetrician-gynecologist. Tearsheet requests to Joseph L. Rauh, M.D., Adolescent Clinic, Cincinnati General Hospital, Department of Pediatrics, Cincinnati, Ohio 45229.

girl's medical, social, and emotional needs.

Almost all of the patients are from low-income families. The clinic is largely funded by grants for patient care from the division of maternal and child health, Ohio Department of Health. Several local foundations and private citizens have contributed funds to purchase equipment.

Patient population. The clinic first prescribed an intrauterine contraceptive device (IUD) for an adolescent in 1965. This 15-year-old was an emotionally disturbed and mentally retarded girl from an inadequate home. She also had asthma and epilepsy. The patient was beginning to act out sexually, and her mother asked for birth control services.

This incident crystallized the thinking of staff members who had, of course, been faced with teenagers' needs for birth control for many months. We decided to establish a comprehensive prenatal care and birth control program for adolescents at Cincinnati General Hospital. We first began giving such care to our patients and then accepted referrals from the hospital's maternity service. From 1965 until mid-1968, a total of 89 parous girls visited the Adolescent Clinic for birth control services.

The 89 girls, who comprise clinic group A, were referred from the following sources:

Source Number

Referred post partum from the hospital's maternity service for contraception.---_---_-_-_-----

Parous girls referred by parents, schools, and other clinics for contraception

Pregnant girls referred for prenatal care, delivery, and post partum contraception

Clinic patients seen for general medical care who became pregnant (1965 to mid-1968)

Total 18

The mean age of the Adolescent Clinic group A girls was 16.3 years (table 1). Age at risk was calculated at the time of the girl's first post partum appointment in the clinic for initiation of birth control services. A girl who was seen prenatally in the 
clinic was considered at risk from the date of her delivery. The range of length of followup for the 89 girls was 5 to 53 months, with a mean of 25 months. Followup for these girls was completed by mid-1969.

Ninety-one percent of the clinic girls were Negro. Seventy-one ( 80 percent) were primiparas at risk and 18 were multiparas. Four of the multiparas had had three pregnancies at the time of their first clinic visit. At risk, only 8 percent were married; by the end of the observation period 35 percent were married.

The median school grade completed was ninth grade at the start of the at-risk period and 10th grade at the end of observation. There was no racial difference in respect to education level. Twenty-one girls had completed high school by the end of observation (table 1).

\section{Prenatal Complications and Birth Weights}

Immediately before starting the prenatal care and birth control program, the clinic staff late in 1965 began to compile data concerning pregnancies of

\section{Table 1.-Comparison of two groups of parous adolescents at risk for repeat pregnancy who were delivered at Cincinnati General Hospital}

\begin{tabular}{|c|c|c|}
\hline Characteristic & $\begin{array}{l}\text { Survey } \\
\text { group }\end{array}$ & $\begin{array}{c}\text { Clinic } \\
\text { group A }\end{array}$ \\
\hline $\begin{array}{l}\text { Number patients at risk } \\
\text { Number patients lost to followup. } \\
\text { Total patients }\end{array}$ & $\begin{array}{r}83 \\
7 \\
76\end{array}$ & $\begin{array}{r}89 \\
0 \\
89\end{array}$ \\
\hline $\begin{array}{l}\text { Number white } \\
\text { Number Negro. }\end{array}$ & $\begin{array}{l}23 \\
60\end{array}$ & $\begin{array}{r}8 \\
81\end{array}$ \\
\hline Mean age (years) $\ldots$ & 16. 0 & 16. 3 \\
\hline $\begin{array}{l}\text { Education: } \\
\text { Median grades completed at risk } \\
\text { Median grades completed at end of } \\
\text { observation period } \\
\text { Number completing high school at } \\
\text { end of observation period. }\end{array}$ & $\begin{array}{r}8 \\
10 \\
5\end{array}$ & $\begin{array}{r}9 \\
10\end{array}$ \\
\hline $\begin{array}{l}\text { Marital status: } \\
\text { Number married at risk } \\
\text { Number married at end of observa- } \\
\text { tion period. }\end{array}$ & $\begin{array}{l}21 \\
39\end{array}$ & $\begin{array}{r}7 \\
31\end{array}$ \\
\hline $\begin{array}{l}\text { Observation period: } 2 \\
\text { Mean number of months } \\
\text { Range of months }\end{array}$ & $\begin{array}{r}34 \\
28-40\end{array}$ & $\begin{array}{r}25 \\
5-53\end{array}$ \\
\hline
\end{tabular}

1 Immediately after delivery until end of the observation period. For 57 clinic girls who were post partum when first seen at the Adolescent Clinic, at risk began at the time of the first visit.

2 Observation period for survey girls began at time of delivery in 1964-65 until Dec. 31, 1967; for clinic group A, from delivery or when first seen in the clinic until June 30 , 1969. adolescents who delivered at Cincinnati General Hospital. Information was obtained from the maternity service on all deliveries occurring from September 1, 1964, through August 31, 1965.

Of the 3,060 deliveries during the 12 months, 250, or 8 percent, were of girls 16 years old or younger. The incidence of prematurity was 26 percent for those under 17 compared with 14 percent for the 2,810 women who were 17 or older. Both percentages are high when compared with a national incidence of 7 percent for women who were 21 or older (1). Incidence of prematurity among the patients of three staff obstetricians in private practice in Cincinnati was 3 to 5 percent (unpublished data compiled by R. L. B.).

None of the 250 girls under 17 had attended the Adolescent Clinic. Some attended the adult prenatal clinic at the hospital, others attended neighborhood clinics, and their charts were not available. Many received no prenatal care. The clinic staff could not tabulate meaningful data on prenatal visits, and therefore we were limited to retrospective study of data obtained from hospital charts.

The significantly higher incidence of prematurity (as well as other complications of pregnancy) among the adolescents delivering at Cincinnati General Hospital influenced the staff of the Adolescent Clinic to devote more time and effort to pregnant girls.

Patient population. After the 1965 survey was completed, we felt that further data on a subsample of the 250 girls would be valuable. We selected a random sample of 83 girls from the survey. We wanted to compare the number of repeat pregnancies, their rapidity of occurrence, and use of contraceptives among the survey girls and the 89 girls in Adolescent Clinic group A. We also wanted to compare complications of pregnancy and delivery among the survey girls and the 52 girls in Adolescent Clinic group B, pregnant girls who received comprehensive prenatal care at the clinic.

We carefully reviewed the hospital records of the 83 survey girls and also interviewed 76 of them at the clinic or by telephone. Seven girls were lost to followup. Followup of the survey group ranged from a minimum of 28 months to a maximum of 40 months.

At the beginning of the observation period, that is, at delivery of their infants, the mean age of the survey group was 16 years. For 69 girls, it was the first pregnancy, for 13, the second pregnancy, 
and for one, the third. Regardless of parity, a survey girl was considered at risk for further pregnancies from the date of the survey delivery until the end of 1967.

Data on the racial composition of the survey group are given in table 1 . The median grade level for both the 60 Negro and 23 white girls at risk was the eighth grade. At the end of the observation period, the white girls were still at the eighth grade level but the Negro girls had achieved a median level of. 10th grade. Only five survey girls had finished high school by the end of 1967. Data on their marital status at the time of their deliveries and at the end of observation are given in table 1 .

Prenatal care and delivery. To measure the effects of the clinic's comprehensive care, we compiled data on major complications of pregnancy and delivery for the 83 girls in the survey group and for the 52 girls in clinic group B. The clinic group was followed prenatally from at least the end of the second trimester until term. They were seen monthly until the ninth month of pregnancy and then weekly. Clinic group B was composed of three subgroups:

Source Number

Referred to the clinic already pregnant for prenatal care, delivery, and post partum contraception (1965-mid-1968)

Patients seen for general medical care who became pregnant (1965-mid-1968) --_-_---_--

Additional patients seen for prenatal care (mid1968-mid-1969)

Total

Eight of 32 girls admitted to the clinic before June 30, 1968, had a second pregnancy before June 30, 1969, the cutoff date for Adolescent Clinic patients in the study. Forty-six ( 77 percent) of the 60 pregnancies of the clinic patients were without significant problems compared with 42 (51 percent) of the 83 in the survey group (table 2). If the complications at delivery are eliminated, the percentage of Adolescent Clinic pregnancies with no obstetric problems was 90 percent.

The incidence and type of complications at delivery were similar for both groups. The diagnoses were those recorded by the obstetrics house staff at the time of discharge from the maternity service. Complications included post partum hemorrhage, prolonged labor, cesarean section for cephalo-pelvic disproportion, and urinary tract infections.

Table 2 shows a striking difference between the two groups in the incidence of pre-eclampsia, anemia, and other prenatal complications. The greatest difference was in the incidence of pre-eclampsiaonly four cases ( 7 percent) in the 60 pregnancies of clinic patients compared with 21 cases ( 25 percent) in the 83 pregnancies of the survey group.

Birth weights. Only four Adolescent Clinic pregnancies resulted in premature infants. Three infants weighed more than 2,400 grams. One patient delivered, after 36 weeks' gestation, a normal infant weighing 1,890 grams. Sixteen pregnancies (19 percent) in the survey group resulted in babies weighing less than 2,500 grams. Two survey girls had abortions (babies born dead weighing up to 1,000 grams); two delivered premature infants weighing between 2,000 and 2,500 grams.

\section{Prevention of Repeat Pregnancy}

Table 3 compares the number of repeat pregnancies and total number of pregnancies for the survey group and clinic group A. Sixteen (21 percent) of 76 survey girls avoided further pregnancy, while 60 (67 percent) of 89 Adolescent Clinic girls remained nonpregnant. The survey girls had a total of 84 pregnancies during the 28- to 40-month followup. Clinic group a girls had 38 pregnancies during a considerably wider range of followup, 5 to 53 months. These data suggest that the clinic girls conceived roughly half as frequently as the survey group, even if the shorter observation period for the clinic group is taken into account.

The total number of pregnancies was computed

Table 2.-Comparison of major prenatal and delivery complications in survey group and Adolescent Clinic group B

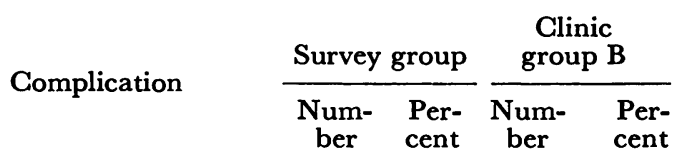

\begin{tabular}{|c|c|c|c|}
\hline $\begin{array}{l}\text { None-eclampsia } \\
\text { Anemia, severe } \\
\text { Third trimester bleeding } \\
\text { Pre-eclampsia and anemia.-- } \\
\text { Pre-eclampsia and bleeding-- } \\
\text { Pre-eclampsia, bleeding, and }\end{array}$ & $\begin{array}{r}42 \\
21 \\
7 \\
1 \\
3 \\
2\end{array}$ & $\begin{array}{r}51 \\
25 \\
8 \\
1 \\
4 \\
3\end{array}$ & $\begin{array}{r}46 \\
4 \\
2 \\
0 \\
0 \\
0\end{array}$ \\
\hline $\begin{array}{l}\text { anemia } \\
\text { Complications at delivery }\end{array}$ & $\begin{array}{l}1 \\
6\end{array}$ & $\begin{array}{l}1 \\
7\end{array}$ & $\begin{array}{l}0 \\
8\end{array}$ \\
\hline Tota & 83 & 10 & 260 \\
\hline
\end{tabular}

1 Post partum endometritis, post partum hemorrhage, prolonged labor, cesarean section for cephalo-pelvic disproportion, and urinary tract infections.

2 Eight girls in clinic group B had a second pregnancy. 
Table 3.- Comparison of repeat pregnancies in survey group and Adolescent Clinic group A during observation periods

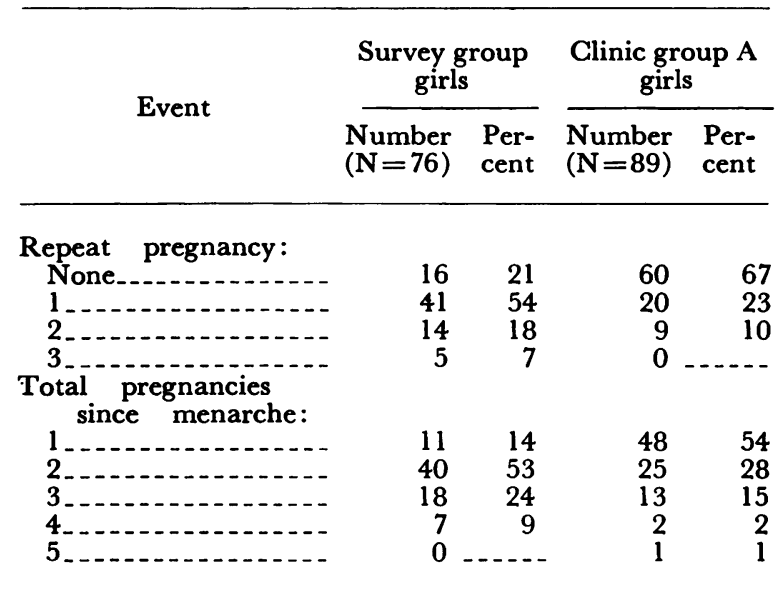

from menarche until the end of each group's observation period. No data were available to determine mean menarcheal age for the survey group; the mean menarcheal age of the Adolescent Clinic patients (determined retrospectively by interview) was 11 years and 11 months.

Rapidity of repeat pregnancy. Table 4 compares the onset of the next pregnancy to the number of months at risk, that is, the months following delivery or, for most clinic group A patients, the months following the first visit to the clinic. The difference in the repeat pregnancy rate at 3 months was almost identical, 4 percent for the survey group and 5 percent for the clinic group.

Subsequently, there was an increasing disparity between the two groups in regard to "how fast pregnant again." At 12 months almost half the survey group had become pregnant again compared with 13 percent of the clinic group. At the end of observation, 79 percent of the survey group had had at least one repeat pregnancy as compared with 33 percent of the clinic girls. The data on the survey girls closely agree with those of Sarrel and Davis (2) who studied adolescents of similar ethnic and socioeconomic background in New Haven, Conn. These workers determined that within 5 years 95 of 100 girls who were primiparas and without birth control services became pregnant again.

Initial contraceptive method. The initial method of contraception for both groups is summarized in table 5. Only 30 survey girls used contraceptives. Twenty-nine took pills and one had an IUD, the Lippes loop, inserted. Table 5 indicates that only four of the 76 girls started contraception during the first 6 months at risk, a crucial period for the young girl in terms of her future education, decision making, and family planning.

In contrast, all 89 girls in clinic group A were offered contraceptives and 81 started using them56 the Lippes loop and 25 oral pills. Eight clinic girls never returned after one or two initial visits to start contraception. Six became pregnant again.

We initially recommended the IUD more often than pills because of the difficulty adolescents have in taking oral medication consistently. The choice of treatment is discussed with each patient as well as with her parent. Signed permission by the patient's parents is required before an IUD is inserted. All insertions as well as the supervision of oral therapy have been under the direction of R. L. B.

Contraceptive failures. Twenty-nine clinic group A patients became pregnant again during the atrisk observation period. The reasons for contraceptive failure were as follows:

Reason

Number of girls

Oral contraceptive begun, discontinued by patient

Never returned for contraceptives

Lippes loop expelled 1 or more times, oral contraceptives begun and discontinued by patient.-

Repeated expulsion of Lippes loop, patient pregnant before returning to the clinic

Lippes loop removed by other clinic or at patient's request because of bleeding, cramps, or apprehension

Pregnant with Lippes loop in situ

Pregnant at time of first visit.

Only two girls had method failures-both became pregnant again with the IUD in situ; 27 were unable to adjust to contraceptives or to cooperate

Table 4.-Comparison of rapidity of next pregnancy during risk period of 76 survey group girls and 89 Adolescent Clinic group A girls

\begin{tabular}{llcc} 
Group and interval & $\begin{array}{l}\text { Number } \\
\text { pregnant }\end{array}$ & $\begin{array}{c}\text { Cumula- } \\
\text { tive } \\
\text { number } \\
\text { pregnant }\end{array}$ & $\begin{array}{c}\text { Cumula- } \\
\text { tive } \\
\text { percent } \\
\text { pregnant }\end{array}$ \\
\hline
\end{tabular}

Survey group:

At 3 months.........

At 6 months. ......

At 12 months. .....

At 24 months.......

End of observation...

Clinic group A:

At 3 months.......

At 6 months......

At 12 months. . .....

At 24 months. . . . . -

End of observation.-.

$\begin{array}{rrr}3 & 3 & 4 \\ 11 & 14 & 18 \\ 19 & 33 & 44 \\ 20 & 53 & 70 \\ 7 & 60 & 79 \\ & & \\ 4 & 4 & 5 \\ 6 & 10 & 11 \\ 6 & 16 & 18 \\ 11 & 27 & 30 \\ 2 & 29 & 33\end{array}$

.

\section{.}


with the clinic well enough to begin or continue using them. These results suggest that our contraceptive failures were patient failures.

P. M. Sarrel, director of the Yale-New Haven Young Mothers Program, in a personal communication to J. L. R. in March 1970 suggested that the adolescent's difficulty in adjustment to and cooperation with taking cyclic hormone pills may be the result of lack of preparation during the prenatal period. The results of Sarrel and Kierman (3) with oral contraceptives among a similar group of girls who received intensive educational services during pregnancy have been more impressive.

Majzlin spring device. Our experience with the Lippes loop was disappointing because of the high incidence of expulsions (4). The 55 percent expulsion rate was approximately six times that expected for adult women (5). Expulsions are more common among young women and primiparas than among old women and multiparas. Nevertheless, by early 1968 we began inquiring about other types of intrauterine devices. R. L. B. became interested in the Majzlin spring device. This nickel-chromesteel alloy device is lodged at a higher point in the fundus of the uterus than is the Lippes loop and does not have a funnel shape at its lower edge. The expulsion rate at initial insertion for the Majzlin spring device among adult women is reported to be 2 percent in contrast to an expulsion rate of 8 percent for the Lippes loop $(6)$.

By mid-1968 we began to use the Majzlin spring device in the Adolescent Clinic. Since then, 60 patients have had this IUD inserted. Some were girls who initially had expelled a Lippes loop one to three times. The Majzlin device was the initial method for others-girls referred to clinic since mid-1968 and followed beyond mid-1969. To date we have had only three expulsions among these 60 girls, a rate ( 5 percent) approximately twice that for adult women (4).

We have not noticed among parous girls any significant difference in the incidence of severity of post insertion cramps with the Majzlin device as compared with the Lippes loop. The incidence of such cramps is distinctly lower in nulliparous girls. However, the incidence of intermenstrual bleeding for several months after the insertion of the Majzlin IUD is higher than that with the Lippes loop. The prolonged bleeding usually stops with small doses of estrogen (estrone) given preovularly. The Majzlin spring device is the contraceptive of choice in our clinic at present.
Table 5.-Comparison of initial contraceptive methods used during risk periods, survey group and Adolescent Clinic group A

\begin{tabular}{|c|c|c|c|c|}
\hline \multirow{2}{*}{ Method } & \multicolumn{2}{|c|}{ Survey group } & \multicolumn{2}{|c|}{$\underset{\mathrm{A}}{\text { Clinic group }}$} \\
\hline & $\underset{\text { ber }}{\text { Num- }}$ & $\begin{array}{l}\text { Per- } \\
\text { cent }\end{array}$ & $\underset{\text { ber }}{\text { Num- }}$ & $\begin{array}{l}\text { Per- } \\
\text { cent }\end{array}$ \\
\hline $\begin{array}{l}\text { None } \\
\text { Pills } \\
\text { IUD (Lippes loop) }\end{array}$ & $\begin{array}{r}46 \\
29 \\
1\end{array}$ & $\begin{array}{r}60 \\
38 \\
2\end{array}$ & $\begin{array}{r}8 \\
25 \\
56\end{array}$ & $\begin{array}{r}9 \\
28 \\
63\end{array}$ \\
\hline Total & 76 & 100 & 89 & 100 \\
\hline $\begin{array}{l}\text { Contraception begun } \\
\text { within } 6 \text { months at } \\
\text { risk. }\end{array}$ & 4 & 5 & 81 & 91 \\
\hline
\end{tabular}

Nulliparous girls. The results discussed up to this point have only included data concerning parous girls. Dempsey recently reviewed the incidence of pregnancy among 15-year-olds in Baltimore and found it to be considerably higher among parous girls as compared with the nulliparous $(\boldsymbol{y})$. In addition, some limitation on our clinic data was necessary to make the clinic group as comparable as possible with the survey group. We have given a number of nulliparous girls contraceptives. These girls usually have had a chronic medical problem such as the 15-year-old girl already described. Our experience with nulliparous girls has been similar to that with parous patients-the adolescent has difficulty adjusting to oral therapy and the IUD is the method of choice.

The IUD is especially helpful with the mentally retarded adolescent who cannot take oral medication by herself. To date we have inserted two Lippes loops and seven Majzlin spring devices into retarded girls. None of these devices has been expelled, and side effects have been minimal. Four patients required hospitalization and general anesthesia to allow for proper pelvic examination and insertion.

\section{Discussion}

In most respects Adolescent Clinic group A closely resembled the survey group. Their mean ages and socioeconomic backgrounds were identical. Nevertheless, there were marked differences in the proportion of the groups who were Negro, the length of observation, and opportunity for care in the Adolescent Clinic program which may have influenced favorably the prenatal outcome and results with contraceptives of the clinic's patients. In Cincinnati it is accepted that Negro patients avail them- 
selves of medical care more frequently and consistently than white patients of comparable income. Only 9 percent of clinic group A was white compared with 28 percent of the survey group. In addition, the clinic group girls were either referred to or actively involved as patients in the Adolescent Glinic when they were considered at risk for further pregnancy. It may be that the clinic group girls were more motivated to seek birth control services than those who had no contact with the Adolescent Clinic.

By 1967, toward the end of the observation period for the survey group, the Adolescent Clinic was becoming known within Cincinnati General Hospital for its willingness to accept young girls and give them contraceptives. It should also be emphasized that the survey group deliveries occurred in 1964 and 1965, before the initiation of a maternity and infant care project in Cincinnati and at a time when girls under 18 years were not accepted by Cincinnati's Planned Parenthood clinics. Finally, the Adolescent Clinic patients undoubtedly received more individual medical, obstetric, educational, and personal attention than the survey girls who attended adult clinics.

Nevertheless, we feel that none of these differences in time or complexion of the two groups should vitiate the results or argue against the establishment of multidisciplinary comprehensive care programs for young mothers. Since both groups were treated by the hospital house staff when in labor, differences in prenatal complications and birth weights represent only the effect of prenatal care. The success of the Cincinnati Adolescent Clinic program was similar to that of programs administered by other obstetric departments, especially the Young Mothers Program at Yale-New Haven Medical Center (8) and the Y-Med Program in Syracuse, N.Y. (9) .

We have emphasized our method of operation and the statistical success of our program. We feel that it is also important to comment on the philosophy that underlies the program. The problems of the pregnant teenager certainly are not new. Fortunately, many health disciplines have recently become concerned with how to break the self-defeating cycle of out-of-wedlock pregnancy, school loss, oneparent family struggle, lack of vocational competence, financial dependency, and repeat pregnancy. The physicians in the Adolescent Clinic planned the program described with the premise that competent medical personnel already available could work at such a multidisciplinary clinic to change this cycle for the individual young woman. The teenager-oriented program provides easily available services. Crucial to success is an open, trusting relationship between the adolescent and her physician. With this relationship as a foundation, we hoped that our patients would acquire enough self-interest to break out of the cycle. The results suggest that many of our patients accomplished this.

Prenatal complications of pregnancy were greatly reduced, with a resulting decrease in the incidence of severe prematurity. Whereas less than half of the survey group accepted birth control, a high percentage of the Adolescent Clinic girls accepted some form of birth control within a brief time after the delivery of their infants. Subsequently, a significant reduction in the well-demonstrated incidence of repeat pregnancy in this high-risk group was seen. All of the girls were encouraged to return to school and were helped to plan for it. Twenty-five percent have completed high school, and many are still in school. Several patients are now in college. Osofsky and co-workers (9) and Sarrel and Kierman (3) also reported the attainment of a significantly higher scholastic level among post partum girls in their programs.

More important, the results indicate that with such a program the individual can become selfdetermining. For example, T. M., now 22 and married, came to the clinic in 1965 following a pregnancy without prenatal care and a delivery during which her hemoglobin fell to a very low level. She had an IUD inserted, returned to school, and finished high school. After using the IUD for 3 years, she recently requested removal so that she could plan her family with her husband.

We would like to be able to state that the success of the program is also a success with each patient. Unfortunately, there are teenagers with whom this approach cannot succeed; for example, those with emotional problems for which pregnancy provides a solution or escape or those with defeating family or social situations which cannot be changed. Such patients become treatment failures regardless of the best efforts of the team or the method of treatment. Our birth control program includes three adolescent family members who live together in a situation which has fostered six out-of-wedlock pregnancies. Each girl originally came to the Adolescent Clinic as a primipara and had a subsequent pregnancy in spite of the brief use of both oral and IUD contraceptive methods. 


\section{REFERENCES}

(1) Danforth, D. N.: Textbook of obstetrics and gynecology. Hoeber Medical Division, Harper \& Row, Publishers, Inc., New York, 1966, p. 580.

(2) Sarrel, P. M., and Davis, C. D.: The young unwed primipara. Amer J Obstet Gynec 95: 722-725, July 1966.

(3) Sarrel, P. M., and Kierman, L. V.: The young unwed mother. Amer J Obstet Gynec 105 : 575-578, October 1969 .

(4) Johnson, L. B., Burket, R. L., and Rauh, J. L.: Successful use of an intrauterine device in adolescence. Clin Pediat. In press.

(5) Lippes, J.: Contraception with intrauterine plastic loops. Amer J Obstet Gynec 93: 1024-1030, December 1965.
(6) Solish, G. I., and Majzlin, G.: The Majzlin spring IUCD. Proceedings of the sixth annual meeting of the American Association of Planned Parenthood Physicians. In Advances in Planned Parenthood, IV., pp. 73-79, San Antonio, Tex., April 1968.

(7) Dempsey, J. J.: Illegitimacy in early adolescence. Amer J Obstet Gynec 106: 260-265, January 1970.

(8) Sarrel, P. M., Holley, M., and Anderson, G.: The young unwed mother. Obstet Gynec 32: 741-747, December 1968.

(9) Osofsky, H. J., Hagen, J. H., and Wood, P. W.: A program for pregnant school girls. Amer J Obstet Gynec 100: 1020-1027, April 1968.

RAUH, JOSEPH L. (Gincinnati General Hospital), JOHNSON, LOIS B., and BURKET, ROBERT L.: The management of adolescent pregnancy and prevention of repeat pregnancies. HSMHA Health Reports, Vol. 86, January 1971, pp. 66-73.

The Adolescent Clinic at Cincinnati General Hospital gives comprehensive care to pregnant girls and, after their deliveries, offers birth control counseling and contraceptives as well as assistance in returning to school. Prenatal complications in 60 pregnancies of clinic patients were compared with those occurring in a survey group of 83 girls. All young women in both groups were delivered by the intern and resident house staff of the hospital; most were under 17 years old. Incidence of preeclampsia was 7 percent in the clinic group and 25 percent in the survey group. Four premature infants were born to clinic patients and 16 to survey group mothers.

The survey group, followed for a mean period of 34 months (range 24-40 months) was also compared with 89 Adolescent Glinic patients followed for a mean of 25 months (range 5-53 months) who were counseled on birth control and offered contraceptives. Only 16 of 76 in the survey group (seven were lost to followup) avoided further pregnancies; the remainder had a total of 84 pregnancies. 'The Adolescent Clinic patients had a total of 38 pregnancies, and 60 girls remained nonpregnant.

The two groups also differed in the rapidity of repeat pregnancies; after 24 months 70 percent of the survey group but only 30 percent of the clinic patients were pregnant. At 6 months post partum, 91 percent of the clinic patients were using contraceptives compared with 5 percent of the survey group. At the end of their observation periods, 21 clinic patients and five survey group girls had completed high school.

Because of a high rate of expulsion of Lippes loops among clinic patients, the staff in mid-1968 began inserting Majzlin spring devices. This IUD is now the clinic's contraceptive of choice. Only three expulsions have occurred among 60 patients. 